\title{
Angiogenesis in the Treatment of Non-Small Cell Lung Cancer
}

\author{
Leora Horn ${ }^{1}$ and Alan B. Sandler ${ }^{1}$ \\ ${ }^{1}$ Vanderbilt Ingram Cancer Center, Vanderbilt University, Nashville, Tennessee
}

\begin{abstract}
Lung cancer is the leading cause of cancer-related mortality in the United States. Patients with advanced disease have a median survival of approximately 10 months when treated with standard platinumbased therapy. Improvements in our understanding of cancer biology have led to the development of novel agents that more precisely affect the target of interest, allowing for a more rational approach to clinical trial design. Angiogenesis, the growth of new vessels from pre-existing vessels, is a fundamental step in tumor growth and progression. Inhibition of tumor-related angiogenesis has become an attractive target for anticancer therapy. A large randomized trial demonstrated an improvement in overall survival when bevacizumab, a monoclonal antibody against vascular endothelial growth factor (VEGF), was combined with chemotherapy in patients with advanced non-small cell lung cancer (NSCLC). Small molecule inhibitors targeting both the VEGF receptor (VEGFR) and the tyrosine kinase receptor have also shown promise when combined with standard chemotherapy, but their role in the treatment of patients with NSCLC remains to be determined. This paper reviews clinical trials that have incorporated antiangiogenic agents in the treatment of patients with NSCLC.
\end{abstract}

Keywords: angiogenesis; targeted therapy; vascular endothelial growth factor; oral multikinase inhibitors

Lung cancer is the leading cause of cancer-related mortality in the United States, with 213,380 new cases and 160,390 deaths anticipated in 2008 (1). Non-small cell lung cancer (NSCLC) accounts for 80 to $85 \%$ of cases, with approximately $70 \%$ of patients presenting with advanced disease (stage IIIB with pleural effusion or stage IV) at the time of diagnosis. Patients with advanced disease have a median survival (OS) of approximately 10 months when treated with traditional platinum-based therapy (2). Therefore, novel therapies are required for this all too common disease. Our improved understanding of cell biology has allowed for the development of novel therapies with potentially complimentary antitumor activity. Tumor growth and development is a complex multistep process requiring the transformation of a normal cell into a malignant cell. In the last two decades there has been substantial interest in developing agents that modulate growth factors and signaling cascades that are aberrant in tumor cells. Small tumors $(<2 \mathrm{~mm})$ are quiescent, extracting oxygen and nutrients via diffusion (3). Angiogenesis, the growth of new vessels from preexisting vessels, is a fundamental step in the transition of tumors from the dormant to malignant stage $(4,5)$. The secretion of proangiogenic factors, during tumor growth and progression, results in cell migration, proliferation, and capillary tube formation. Tumor blood vessels, however, have abnormal structural arrangement. Antiangiogenic agents, in addition to inhibiting the growth of

(Received in original form July 7, 2008; accepted in final form August 30, 2008) Correspondence and requests for reprints should be addressed to Alan B. Sandler, M.D., Vanderbilt Ingram Cancer Center, Vanderbilt University, 777 Preston Research Building, 2200 Pierce Ave., Nashville, TN 32323-6307. E-mail: alan. sandler@vanderbilt.edu

Proc Am Thorac Soc Vol 6. pp 206-217, 2009

DOI: 10.1513/pats.200807-066LC

Internet address: www.atsjournals.org tumor vasculature, are thought to transiently normalize the tumor vascular supply, resulting in improved drug delivery $(6,7)$. Angiogenesis has also been implicated in the growth of distant metastases (8-10). Microvessel count (MVC) as a measure of angiogenesis is a significant predictor of increased risk of metastatic disease and worse overall survival in patients with NSCLC $(11,12)$. Therefore, angiogenesis has become a rational therapeutic target, given the important role it plays in tumor growth and development. Because of their nonoverlapping toxicity with chemotherapy agents, antiangiogenic agents have been combined with a variety of chemotherapy agents currently used in the treatment of patients with NSCLC. In this review, we summarize the data for antiangiogenic agents that have been approved and are in development for the treatment of patients with NSCLC (see Tables 1 and 2).

\section{ANTIVASCULAR ENDOTHELIAL GROWTH FACTOR MONOCLONAL ANTIBODIES}

\section{Combining Bevacizumab with Chemotherapy}

Vascular endothelial growth factor (VEGF) mediates proangiogenic effects. VEGF is produced by both normal cells within the body as well as by tumor cells, suggesting that VEGF signaling is mediated through both paracrine and autocrine mechanisms (13). Many human cancer cells, including lung cancer cells, express VEGF receptors (VEGFR) $(14,15)$. VEGF expression has been found to significantly correlate with new vessel formation, disease-free survival (DFS), and overall survival (OS) in patients with NSCLC $(14,16,17)$. Bevacizumab is a monoclonal antibody with a high affinity for VEGF $(18,19)$. Bevacizumab exerts its antiangiogenic effects by binding to free, circulating VEGF, thereby inhibiting the binding of VEGF to its receptors, preventing VEGF ligand-receptor downstream signaling (19).

A randomized phase II trial of 99 patients with advanced or recurrent NSCLC compared carboplatin and paclitaxel with or without bevacizumab $(7.5$ or $15 \mathrm{mg} / \mathrm{kg})$. Patients who did not progress during chemotherapy continued on single-agent bevacizumab for up to 18 cycles. Patients with progressive disease who had received chemotherapy alone went on to receive singleagent bevacizumab. The combination of bevacizumab $(15 \mathrm{mg} / \mathrm{kg})$ with carboplatin and paclitaxel increased response rate (RR) (31.5\% versus $18.8 \%$ ) and prolonged time to progression (median 7.4 versus $4.2 \mathrm{mo} ; P=0.023$ ) compared with chemotherapy alone. There was also a nonsignificant improvement in OS, 17.7 months versus 14.9 months. This was not seen at the lower bevacizumab dose $(7.5 \mathrm{mg} / \mathrm{kg})$, for which the time to progression was 4.3 months and OS was 11.6 months. Although there were no objective responses, 1 -year survival was $47 \%$ for patients $(n=19)$ who progressed and went on to receive single-agent bevacizumab $(15 \mathrm{mg} / \mathrm{kg})$. A higher incidence of bleeding was noted in the bevacizumab-treated patients. Severe pulmonary hemorrhage, which was observed in six patients $(9.1 \%)$ and led to four fatalities, was associated with squamous cell histology, tumor cavitation, central tumors, and disease location close to major blood vessels (20). Based on these results, ECOG conducted a phase III trial (E4599) comparing carboplatin and paclitaxel 
TABLE 1. ANTIANGIOGENIC AGENTS APPROVED OR IN DEVELOPMENT FOR THE TREATMENT OF PATIENTS WITH NON-SMALL CELL LUNG CANCER

\begin{tabular}{|c|c|c|c|c|}
\hline Drug & Target & $\begin{array}{c}\text { Route of } \\
\text { Administration }\end{array}$ & $\begin{array}{l}\text { Frequency of } \\
\text { Administration }\end{array}$ & Clinical Status \\
\hline Bevacizumab & VEGF ligand & IV & Every $3 \mathrm{wk}$ & Approved \\
\hline Sorafenib & $\begin{array}{l}\text { Raf, Kit, Flt-3, VEGFR-2, VEGFR-3, } \\
\text { PDGFR- } \beta\end{array}$ & $\mathrm{PO}$ & Twice daily & Phase III \\
\hline Vandetanib & VEGFR-2, VEGFR-3, RET, EGFR & $\mathrm{PO}$ & Daily & Phase III \\
\hline Sunitinib & $\begin{array}{l}\text { VEGFR- } 1 \text {, VEGFR-2, VEGFR-3, } \\
\text { PDGFR- } \alpha, \text { PDGFR- } \beta \text {, Flt-3, c-kit }\end{array}$ & $\mathrm{PO}$ & Twice daily & Phase III \\
\hline Cediranib & $\begin{array}{l}\text { VEGFR-2, VEGFR-1, VEGFR-3, } \\
\text { c-kit, Flt-3 }\end{array}$ & PO & Daily & Phase III \\
\hline Motesanib & $\begin{array}{l}\text { VEGFR-1, VEGFR-2, VEGFR-3, } \\
\text { PDGFR, Ret, kit }\end{array}$ & $\mathrm{PO}$ & Daily & Phase III \\
\hline Axitinib & $\begin{array}{l}\text { VEGFR-1, VEGFR-2, VEGFR-3, } \\
\text { PDGFR- } \beta \text {, kit }\end{array}$ & $\mathrm{PO}$ & Twice daily & Phase II \\
\hline Pazopanib & $\begin{array}{l}\text { VEGFR-2, VEGFR- } 2 \text {, VEGFR-3, } \\
\text { PDGFR- } \alpha, \text { PDGFR- } \beta \text {, c-kit }\end{array}$ & $\mathrm{PO}$ & Daily & Phase II \\
\hline XL647 & VEGFR-2, EGFR, erbB2, EphB4 & $\mathrm{PO}$ & Daily/twice daily & Phase II \\
\hline
\end{tabular}

Definition of abbreviations: EGFR = epidermal growth factor receptor; PDGFR = platelet-derived growth factor receptor; VEGF = vascular endothelial growth factor; VEGFR = VEGF receptor.

with or without bevacizumab $(15 \mathrm{mg} / \mathrm{kg})$ in 878 patients with nonsquamous cell histology recurrent or advanced NSCLC. There was a significant improvement in RR, OS, and progression-free survival (PFS) for patients treated with bevacizumab plus chemotherapy compared with chemotherapy alone, 12.3 versus 10.3 months (hazard ratio [HR] $0.79 ; P=0.003$ ), 6.2 versus 4.5 months $(\mathrm{HR}, 0.66 ; P<0.001)$ and $35 \%$ versus $15 \%(P<$ $0.001)$, respectively. In a prespecified subset analysis, the benefit of bevacizumab plus chemotherapy on OS was evident among men (11.1 versus $8.7 \mathrm{mo}$ ) but not women (13.3 versus $13.1 \mathrm{mo}$ ), compared with chemotherapy alone. Response rate and PFS were statistically significantly improved in both sexes. There was a significantly higher incidence of hematologic toxicities, febrile neutropenia, hemorrhage, hypertension, and proteinuria for bevacizumab-treated patients. There were 15 treatment-related deaths among patients receiving bevacizumab-based therapy, including five from pulmonary hemorrhage (21). Biological correlates including basic fibroblast growth factor (bFGF), Eselectin, VEGF, and intercellular adhesion molecule (ICAM) were measured prospectively in all patients. Patients with low baseline ICAM levels had a significantly better overall survival $(P=0.00005)$ and 1-year survival compared with those with high ICAM levels ( $65 \%$ versus $25 \%$ ). A test for treatment by factor interaction was also significant for ICAM $(P=0.04)$, suggesting a benefit from treatment with bevacizumab in patients with low baseline ICAM levels but no benefit for patients with high levels. No other correlates were found to be significant for treatment effect (22). An unspecified retrospective subset analysis of elderly patients ( $\geqslant 70 \mathrm{yr}$ of age), $26 \%$ of study patients, found a trend to toward higher RR and PFS but no difference in OS for paclitaxel and carboplatin versus paclitaxel and carboplatin plus bevacizumab (17\% versus $29 \%, 4.9$ versus 5.9 mo and 12.1 versus 11.3 mo, respectively). Paclitaxel and carboplatin plus bevacizumab was also associated with a significantly higher incidence of grade 3 to 5 toxicities in elderly patients (61\% versus $87 \%, P<0.001)(23)$. Based on the results of E4599, ECOG is conducting a phase III randomized trial in 1,500 patients evaluating the addition of bevacizumab to standard chemotherapy (cisplatin and gemcitabine, cisplatin and vinorelbine, or cisplatin and taxotere) in the adjuvant setting. Carboplatin and paclitaxel is not being used after the LACE meta-analysis demonstrated superior outcomes for patients treated with cisplatin-based regimens in the adjuvant setting (24). Patients randomized to bevacizumab will receive bevacizumab $(15 \mathrm{mg} / \mathrm{kg})$ every 3 weeks for up to 1 year. The primary endpoint for this trial is OS, and secondary endpoints are disease-free survival and toxicity.

A second phase III randomized trial, conducted in Europe and Canada (AVAiL), compared cisplatin and gemcitabine with or without bevacizumab $(7.5 \mathrm{mg} / \mathrm{kg}$ or $15 \mathrm{mg} / \mathrm{kg})$ in 1,043 patients with recurrent or advanced nonsquamous NSCLC (25). After the positive survival results of the ECOG trial, the primary endpoint of AVAiL was amended from OS to PFS. A significant improvement in PFS was seen at both bevacizumab doses: 6.7 months for $7.5 \mathrm{mg} / \mathrm{kg}(\mathrm{HR}, 0.75 ; P=0.003)$ and 6.5 months for $15 \mathrm{mg} / \mathrm{kg}$ (HR, 0.82; $P=0.03)$, compared with 6.1 months for the placebo group. However, OS was not significantly different between treatment groups, but these data have not been formally presented. Objective response rates were $34.1 \%, 30.4 \%$, and $20.1 \%$ for bevacizumab $7.5 \mathrm{mg} / \mathrm{kg}, 15 \mathrm{mg} / \mathrm{kg}$, and placebo, respectively. Although $9 \%$ of patients in the AVAiL trial received therapeutic anticoagulation, severe pulmonary hemorrhage rates were less than or equal to $1.5 \%$ for all arms. The adverse events fatality rate (from any cause) was similar across treatment groups (4-5\%). Although the AVAiL trial was not powered to directly compare the two bevacizumab doses, efficacy and safety data were similar for both doses.

A multitude of phase II trials combining bevacizumab with platinum-based therapy in over 500 chemotherapy-naïve patients with advanced NSCLC are currently ongoing. These include bevacizumab in combination with nab-paclitaxel and carboplatin (26), carboplatin and docetaxel (27), cisplatin and docetaxel (28), carboplatin and pemetrexed $(29,30)$, pemetrexed and oxaliplatin $(31,32)$, oxaliplatin and gemcitabine $(33)$, and gemcitabine and carboplatin (34). The BEACON study is a randomized phase II trial evaluating preoperative chemotherapy (docetaxel and cisplatin) with or without bevacizumab $\left(15 \mathrm{mg} / \mathrm{m}^{2}\right)$ in patients with nonsquamous histology stage IB-IIIA NSCLC. Preliminary results from 19 of an intended 70 patients have shown over $94 \%$ of patients completing preoperative chemotherapy. A similar rate of down-staging has been observed (5/9 in the bevacizumab treatment group and 5/8 in the chemotherapy alone treatment group). Two episodes of bleeding have been reported to date; one patient developed hemoptysis preoperatively and one patient had a GI bleed postoperatively. There were no bevacizumab-related operative complications (35). A phase II trial evaluated second line therapy with pemetrexed and bevacizumab every 3 weeks in 48 patients who had progressed after platinum-based chemotherapy. Major grade $3 / 4$ toxicities ( $>10 \%$ of patients) included 
TABLE 2. SUMMARY OF CLINICAL TRIALS INVESTIGATING ANTIANGIOGENIC THERAPY IN PATIENTS WITH NON-SMALL CELL LUNG CANCER

\begin{tabular}{|c|c|c|c|c|c|}
\hline Trial & Phase & Treatment & Pt No: & OS $(m o)$ & $\operatorname{RR}(\%)$ \\
\hline \multicolumn{6}{|c|}{ Bevacizumab } \\
\hline \multirow[t]{3}{*}{ Johnson (20) } & II & $\mathrm{CBDCA}+\mathrm{Pac}^{*}$ & 32 & 14.9 & 19 \\
\hline & & $\mathrm{CBDCA}+\mathrm{Pac}^{*}+$ Bevacizumab $7.5 \mathrm{mg} / \mathrm{kg}$ & 35 & 11.6 & 28 \\
\hline & & $\mathrm{CBDCA}+\mathrm{Pac}^{*}+$ Bevacizumab $15 \mathrm{mg} / \mathrm{kg}$ & 32 & 17.7 & 35 \\
\hline \multirow[t]{2}{*}{ Sandler (21) } & III & $\mathrm{CBDCA}+\mathrm{Pac}^{*}$ & 427 & 10.3 & 35 \\
\hline & & CBDCA+Pac* + Bevacizumab $15 \mathrm{mg} / \mathrm{kg}$ & 440 & 12.3 & 15 \\
\hline \multirow[t]{3}{*}{ Manegold (25) } & III & CDDP + gem $^{\dagger}$ & 347 & NR & 20 \\
\hline & & CDDP + gem $^{\dagger}+$ Bevacizumab $7.5 \mathrm{mg} / \mathrm{kg}$ & 345 & & 34 \\
\hline & & CDDP + gem ${ }^{\dagger}+$ Bevacizumab $15 \mathrm{mg} / \mathrm{kg}$ & 351 & & 30 \\
\hline Aadjei & II & Pemetrexed + Bevacizumab $15 \mathrm{mg} / \mathrm{kg}$ & 48 & 8.6 & 10 \\
\hline Herbst (44) & $\mathrm{I} / \mathrm{II}$ & Erlotinib + Bevacizumab 15 mg/kg & 40 & 12.6 & 20 \\
\hline \multirow[t]{3}{*}{ Herbst (46) } & II & Docetaxel or pemetrexed & 41 & 8.6 & 12 \\
\hline & & Docetaxel or pemetrexed + bevacizumab $15 \mathrm{mg} / \mathrm{kg}$ & 40 & 12.6 & 13 \\
\hline & & Erlotinib + bevacizumab 15 mg/kg & 39 & 13.7 & 18 \\
\hline \multicolumn{6}{|c|}{ Sorafenib } \\
\hline Gutierrez (60) & II & Sorafenib $400 \mathrm{mg}$ & 15 & NR & 13 \\
\hline Gatzemeir (57) & II & Sorafenib $400 \mathrm{mg}$ & 54 & 7.0 & 29 \\
\hline Aadjei (61) & II & Sorafenib $400 \mathrm{mg}$ & 25 & 8.8 & 12 \\
\hline \multirow[t]{2}{*}{ Schiller } & II & Sorafenib $400 \mathrm{mg}$ & 51 & 11.9 & 2 \\
\hline & & Placebo & 32 & 9.0 & 3 \\
\hline Adjei (63) & 1 & Gefitinib + Sorafenib (200-400 mg) & 31 & NR & $3 \%$ \\
\hline Schiller (64) & $\mathrm{I} / \mathrm{II}$ & CBDCA + Pac* + Sorafenib $(400 \mathrm{mg})$ & 15 & NR & $29 \%$ \\
\hline \multirow[t]{2}{*}{ Scagliotti (65) } & III & $\mathrm{CBDCA}+\mathrm{Pac}^{*}$ & 462 & 10.7 & $24 \%$ \\
\hline & & Sorafenib $(400 \mathrm{mg})+\mathrm{CBDCA}+\mathrm{Pac}^{*}$ & 464 & 10.6 & $30 \%$ \\
\hline \multicolumn{6}{|c|}{ Vandetanib } \\
\hline Nakagawa (71) & II & Vandetanib 100 mg/200 mg/300 mg & 53 & NR & $13 \%$ \\
\hline \multirow[t]{2}{*}{ Natale (72) } & II & Vandetanib 300 mg daily & 83 & 6.1 & 8 \\
\hline & & Gefitinib 250 mg daily & 85 & 7.4 & 1 \\
\hline \multirow[t]{3}{*}{ Heymach (73) } & II & Docetaxel & 41 & 13.4 & 12 \\
\hline & & Docetaxel + Vandetanib 100 mg & 44 & 13.1 & 26 \\
\hline & & Docetaxel + Vandetanib 300 mg & 42 & 7.9 & 18 \\
\hline \multirow[t]{3}{*}{ Heymach (75) } & II & $\mathrm{CBDCA}+\mathrm{PaC}^{*}$ & 52 & NR & 25 \\
\hline & & $\mathrm{CBDCA}+\mathrm{Pac}^{*}+$ vandetanib $300 \mathrm{mg}$ & 56 & & 32 \\
\hline & & Vandetanib & 73 & & 7 \\
\hline \multicolumn{6}{|c|}{ Sunitinib } \\
\hline Socinski (84) & II & Sunitinib 50 mg daily $\ddagger$ & 63 & 5.4 & 11.1 \\
\hline Brahmer (85) & II & Sunitinib 37.5 mg daily ${ }^{\S}$ & 47 & 8.6 & 2 \\
\hline $\operatorname{Reck}(86)$ & I & CDDP + gem ${ }^{\dagger}+$ Sunitinib $(37.5$ mg or 50 mg) & 13 & NR & 23 \\
\hline \multicolumn{6}{|c|}{ Other Agents } \\
\hline Laurie (91) & I & $\mathrm{CBDCA}+\mathrm{Pac}^{*}+$ Cediranib (30 mg or $45 \mathrm{mg}$ ) & 20 & NR & 45 \\
\hline Schiller (99) & II & Axitinib $5 \mathrm{mg}$ & 32 & 12.8 & 9 \\
\hline Miller (105) & II & XL647 & 23 & NR & 4 \\
\hline Rizvi (106) & II & XL647 & 41 & NR & 28 \\
\hline
\end{tabular}

Definition of abbreviations: $\mathrm{OS}=$ overall survival; $\mathrm{NR}=$ not reported; RR = response rate.

* Carboplain and paclitaxel.

† Cisplatin and gemcitabin.

¥ Sunitinib administered daily for 4 wk of 6-wk cycle.

$\S$ Sunitinib administered daily continuously for 4 -wk cycles.

neutropenia, lymphopenia, leucopenia, fatigue, dyspnea, and thrombosis. There were 5 partial response (PR) (10\%) and 19 patients with stable disease (SD). Median PFS and OS were 4.1 months and 8.6 months, respectively (36). While the PFS is longer, the RR and OS are similar to those in a prior study by Hanna and coworkers (37) evaluating treatment with pemetrexed alone.

The trials mentioned above have excluded patients with brain metastases due to the theoretical catastrophic potential if there was intracranial bleeding associated with bevacizumab therapy. A review of 85 patients treated on the ATLAS study (see below) and PASSPORT study, a phase II trial evaluating safety and efficacy of bevacizumab in patients with brain metastases due to nonsquamous NSCLC, was presented at ASCO this year. There were no reports of intracranial bleeding during the main study treatment. Seven patients had grade 3-5 CNS events, including syncope, convulsions, ataxia, leukoence- phalopathy, and cerebellar arteriosclerosis. One patient experienced a grade 2 bleed on post-progression therapy. These data suggest that it may be safe to administer bevacizumab to patients with NSCLC with treated brain metastases; however, we await the final results of the study (38).

Two additional studies have reported on the safety of bevacizumab in patients with advanced NSCLC. The SAiL trial reported on the safety of bevacizumab administration with concurrent cardiovascular or anticoagulation medications in 1,065 patients with advanced NSCLC receiving chemotherapy (up to six cycles) with bevacizumab followed by maintenance bevacizumab until disease progression. Three hundred ninety-six serious adverse events were reported, of which 299 (76\%) had resolved or improved; 64 (16\%) were bevacizumab related. CNS progression was observed in 12 patients $(1 \%)$, and 1 patient had CNS hemorrhage 26 weeks after the last bevacizumab dose (39). At baseline, $31.7 \%$ of patients were on cardiovascular medica- 
tions and $3.4 \%$ of patients were on anticoagulants (the majority of which were heparin). Of patients receiving bevacizumab $14 \%$ reported hypertensive events (3\% were grade 3 or 4 ), $92 \%$ started during treatment with bevacizumab, and $68 \%$ resolved during treatment with bevacizumab. Two hundred twenty-seven bleeding events occurred in 181 patients (17\% of patients), and 19 events occurred in 15 of 87 patients on anticoagulation; all were less than grade 3 . These data suggest that despite precautions taken in prior clinical trials, there appears to be less of a safety risk for patients receiving anticoagulation and no barriers to the management of hypertension in patients receiving bevacizumab therapy (40). ARIES is an observational cohort study (OCS) evaluating the safety and efficacy of chemotherapy with bevacizumab in 248 United States cancer institutions. To date, 621 of a planned 2,000 patients with NSCLC have been enrolled, including patients with brain metastases, therapeutic anticoagulation, older age, and ECOG PS 2 patients. Low rates of serious adverse events have been recorded to date, including venous and arterial thrombosis, gastrointestinal perforation, pulmonary hemorrhage, and reversible posterior leukoencephalopathy syndrome. No episodes of hypertension or wound complications have been reported (41).

\section{Combining Bevacizumab with a Targeted Agent: Erlotinib}

As discussed, the angiogenesis pathway is crucial in lung cancer development. There is also involvement of the EGFR pathway in tumorigenesis (42). Therefore, inhibiting both pathways to exert a greater combined antitumor effect and having fewer nonspecific toxicities than chemotherapy (43) represents a rational therapeutic approach. Erlotinib (Tarceva), an oral HER1/EGFR tyrosine kinase inhibitor, has shown a survival benefit in the treatment of patients with lung cancer in phase III trials, and is approved by the FDA for the treatment of locally advanced or metastatic NSCLC in patients failing at least one prior chemotherapy regimen (42). A Phase I/II trial of 40 patients with advanced, nonsquamous NSCLC who had failed at least one prior chemotherapy regimen demonstrated a $20 \%$ RR, 6.2 months PFS, 12.6 months OS, and no grade 3/4 toxicities when bevacizumab $(15 \mathrm{mg} / \mathrm{kg})$ was combined with erlotinib (44). Retrospective proteomic profiling of 37 patients enrolled in this study identified protein/peptide expression patterns that appear to discriminate between responders and nonresponders to treatment. Prospective studies are planned to validate these results (45). The efficacy of this regimen led to a randomized phase II trial comparing chemotherapy alone (docetaxel or pemetrexed) to chemotherapy plus bevacizumab or bevacizumab plus erlotinib in 120 patients with nonsquamous NSCLC who had progressed after platinum-based chemotherapy. The RR was higher for the erlotinib plus bevacizumab combination $17.9 \%$ versus $12.2 \%$ for chemotherapy alone and $12.5 \%$ for chemotherapy plus bevacizumab. The median PFS, OS, and 1-year survival were superior for patients receiving bevacizumab (3.0 versus 4.8 versus 4.4 months, 8.6 versus 12.6 versus 13.7 months, and $33 \%$ versus $53.8 \%$ versus $57.4 \%$ for chemotherapy versus chemotherapy plus bevacizumab versus erlotinib plus bevacizumab, respectively). Grade 3/4 toxicities were greater in the chemotherapy treatment arms with a higher percentage of patients discontinuing treatment due to adverse events $(24 \%$ for chemotherapy alone versus $28 \%$ for chemotherapy plus bevacizumab and $13 \%$ for erlotinib plus bevacizumab) (46). Based on the results of this study, two pharmaceutical sponsored phase III trials were opened. The BeTa Lung trial will compare treatment with erlotinib to erlotinib plus bevacizumab in 655 patients with nonsquamous NSCLC who have progressed after standard first-line therapy. The ATLAS trial is assessing the efficacy and safety of maintenance bevacizumab with or without erlotinib after four cycles of chemotherapy (carboplatin and paclitaxel, carboplatin and gemcitabine, carboplatin and docetaxel) with bevacizumab in 1,150 patients with advanced NSCLC. The ATLAS trial has closed; preliminary safety data from 598 patients reported major grade $3 / 4$ toxicities $(>10 \%$ of patients) to be hypertension and hemorrhage. Adverse events leading to treatment discontinuation were more prevalent in the carboplatin and docetaxel arm (18\%) leading to discontinuation of this regimen, compared with $12 \%$ and $23 \%$ for carboplatin and paclitaxel and carboplatin and gemcitabine, respectively (47). A smaller simon 2-stage phase II trial evaluating the administration of erlotinib plus bevacizumab in chemotherapynaïve patients is ongoing. Preliminary data from 33 patients indicate major toxicities ( $>10 \%$ of patients) to be rash and diarrhea. The primary endpoint of nonprogression at 6 weeks has been met in $75 \%$ of patients. With a median follow-up of 6.3 months, the median time to progression was 5.5 months (48). More mature data with correlative studies are pending. A phase II trial of 48 patients with chemotherapy naïve advanced NSCLC compared up-front chemotherapy with paclitaxel and carboplatin plus bevacizumab to bevacizumab and erlotinib until disease progression. Major grade $3 / 4$ toxicities ( $>10 \%$ of patients) in the chemotherapy treatment arm included neutropenia and neuropathy while the major toxicity was rash in the erlotinib treatment arm. There was $21 \%$ RR and $26 \%$ of patients had SD for chemotherapy plus bevacizumab versus a $12 \% \mathrm{RR}$ and $52 \%$ of patients with SD for erlotinib plus bevacizumab. Median and 1-year survival for all patients was 12.9 months and $49 \%$, respectively. Those patients who had stable disease or a partial response following initial treatment with erlotinib and bevacizumab had a median survival of 23.2 months versus 6.6 months for those patients who had progressed during therapy $(P<0.001)(49)$.

Therefore bevacizumab appears to be safe and well tolerated when combined with chemotherapy in patients with advanced NSCLC. Two large randomized phase III studies have shown an improvement in PFS when bevacizumab was combined with chemotherapy compared with chemotherapy alone. The ECOG 4599 trial showed the addition of bevacizumab to standard chemotherapy-carboplatin and paclitaxel-also results in an improvement in OS compared with chemotherapy alone. A subset analysis suggests there may be limited benefit in elderly patients. Preliminary data show that bevacizumab appears to be safe in patients with stable, treated brain metastases and those who are anticoagulated; however, these data are preliminary, and cautious clinical judgment is suggested. The combination of bevacizumab and erlotinib also appears promising based on phase II data. While the ATLAS trial will provide valuable information regarding the timing of erlotinib to maintenance therapy with bevacizumab, and the BeTa Lung trial will provide valuable information regarding combination erlotinib and bevacizumab after progression of first-line chemotherapy, neither trial will answer the question of whether up-front therapy with bevacizumab and erlotinib is equivalent (or superior) to chemotherapy plus bevacizumab. Preliminary results from a small phase II trial suggest equivalency but further studies are needed.

\section{SMALL MOLECULE RECEPTOR TYROSINE KINASE INHIBITORS}

\section{Sorafenib}

Sorafenib (Bay 43-9006; Nexavar) is an oral multi-kinase inhibitor targeting both tumor proliferation via inhibition of Raf, stem cell factor receptor (c-kit), fms-like tyrosine kinase-3 
(Flt-3), and angiogenesis by targeting VEGFR-2 and -3 and platelet-derived growth factor $\beta$ (PDGFR- $\beta$.) (50-52) In preclinical models, sorafenib has been found to inhibit tumor growth, including NSCLC cells, when administered alone and/ or in combination with vinorelbine, cisplatin, and gefitinib (53, 54). Phase I studies that have included patients with NSCLC determined sorafenib $400 \mathrm{mg}$ twice daily to be safe and well tolerated $(55,56)$. These studies have demonstrated disease stabilization after treatment with single-agent sorafenib, regardless of prior chemotherapy regimen (55-58). Single-agent sorafenib does not appear to adversely affect health-related quality of life in patients with advanced NSCLC (59).

\section{Single-Agent Sorafenib}

In a multi-center, uncontrolled phase II trial, 54 patients with relapsed or refractory NSCLC received single-agent sorafenib. Patients with squamous cell histology and asymptomatic brain metastases were included, and those with significant bleeding in the prior month were excluded. Median PFS was 11.9 weeks and OS was 29.3 weeks. Although there were no confirmed PR in the 51 evaluable patients, tumor shrinkage was observed in $29 \%$ of patients, while $59 \%$ of patients had SD. The most common toxicities ( $>25 \%$ of patients) were diarrhea, hand-foot syndrome, fatigue, and nausea. Hypertension was also observed in $2 \%$ of patients. Four patients had bleeding events thought to be associated with sorafenib. Of these, three patients had epistaxis, and one patient with a central cavitary lesion and squamous cell histology had a fatal pulmonary hemorrhage (30 d after discontinuing treatment with sorafenib) (57). In a Simon two-stage phase II trial, patients who had failed one prior chemotherapy regimen were treated with sorafenib, and response was evaluated by dynamic contrast enhanced MRI (DCE-MRI). Fifteen patients were evaluable for response. There were 2 PR (13\%) and 7 patients with SD (46\%). Toxicities included those previously mentioned in addition to anemia, hyponatremia, hypokalemia, hypocalcemia, keratoacanthoma, and vasculitis. DCE-MRI showed a reduction in tumor permeability associated with reductions in tumor size $(58,60)$. Accrual to this trial is ongoing at the second stage. In a first-line study, 25 patients with advanced NSCLC were treated with sorafenib before receiving standard chemotherapy. Although the study did not meet stage I efficacy criteria (only one confirmed PR in the first 20 patients), the authors concluded that the median survival of 8.8 months and objective response rate of $12 \%$ suggests that single-agent sorafenib achieves similar activity compared with two-drug combinations and should be considered for combination studies with standard chemotherapy regimens (61). ECOG conducted the largest trial of sorafenib in patients with NSCLC to date (E2501). In this phase II trial, 342 patients who had progressed after two or more chemotherapy regimens were treated with sorafenib for two cycles. Patients who were responding continued on treatment with sorafenib, those with SD were randomized to sorafenib or placebo, and those with progression were taken off study. One hundred seven patients with SD were randomized and 83 were evaluable for response. Eight of 30 patients who were on placebo crossed over to treatment with sorafenib. An error in randomization was discovered by ECOG after 55 patients had been randomized. This was thought not to affect the primary endpoint of the study-the proportion of patients with disease control 2 months after randomization. There were a significantly higher number of patients with disease control (SD/PR/CR) at 2 months in the sorafenib treatment group compared with placebo $(47 \%$ versus $19 \%, P=0.01)$. Median PFS was also significantly longer (3.6 versus $2.0 \mathrm{mo}, P=0.018$ ) and there was a trend toward improvement in OS (11.9 months versus $9.0 \mathrm{mo}$ ). Major grade 3/4 toxicities ( $>10 \%$ of patients) included rash and fatigue. There were two treatment-related deaths, one death due to respiratory tract hemorrhage and another due to renal failure (62).

\section{Combination Therapy}

In a phase I dose escalation trial, 31 patients, 12 with locally advanced or recurrent NSCLC, were treated with sorafenib (200 or $400 \mathrm{mg}$ ) plus gefitnib. An additional 20 patients were treated with single-agent sorafenib or gefitinib for 21 days, followed by a 7-day washout period with crossover to the other agent for 21 days followed by a 7-day washout period and the combination of sorafenib and gefitinib. No dose-limiting toxicities were observed at the sorafenib $200 \mathrm{mg}$ dose. The most common adverse events included dermatologic effects, diarrhea, and elevated ALT, with the latter two being the most common grade $3 / 4$ adverse events. Serious adverse events occurring in one patient included dyspnea, fever, elevated ALT and diarrhea. Although gefitinib had no effect on sorafenib pharmacokinetics, sorafenib did affect the pharmacokinetics of gefitinib. There was $1 \mathrm{PR}$ and 20 patients with SD of greater than or equal to 4 months duration. Sorafenib $400 \mathrm{mg}$ twice daily is the recommended dose for future studies with gefitnib (63). In a phase I/II trial, carboplatin and paclitaxel were combined with sorafenib in patients with advanced NSCLC. An encouraging median PFS of 8.5 months was achieved; $29 \%$ of patients had a PR and $50 \%$ had SD. The most common adverse reactions were similar to those found with single-agent treatment: rash, hand-foot syndrome, and gastrointestinal symptoms. Grade $1 / 2$ bleeding events were seen in three patients (64). A randomized phase III trial (ESCAPE) of 926 chemotherapy-naïve patients with advanced NSCLC compared carboplatin and paclitaxel with or without sorafenib. Those patients with disease control (SD/PR/CR) on the sorafenib arm continued on single-agent sorafenib until disease progression. Patients with squamous cell histology were eligible for this trial; patients requiring therapeutic anticoagulation were not. There was no significant difference in RR $30 \%$ versus $24 \%$, PFS 5.1 versus 5.4 months (HR 1.0, $P=0.514$ ), or OS 10.7 versus 10.6 months (HR 1.16, $P=0.930$ ) for patients receiving chemotherapy with sorafenib compared with chemotherapy alone. In subset analysis, patients with squamous cell histology appeared to have a worse OS when treated with the combination of chemotherapy and sorafenib compared with chemotherapy alone $(8.9 \mathrm{mo}$ versus $13.6 \mathrm{mo}$, HR 1.81). This was true for PFS as well. Major grade $3 / 4$ toxicities ( $>10 \%$ of patients) included neutropenia and thrombocytopenia, which was similar between arms. There were two fatal hemorrhages: esophageal hemorrhage for a patient on placebo, and intraabdominal aorta hemorrhage for a patient receiving sorafenib. There was a higher rate of infection (17\% versus $9 \%$ ) and fatigue (11\% versus $7 \%$ ) for patients receiving sorafenib in combination with chemotherapy. There were 21 grade 5 toxicities including 16 episodes of infection, 2 of thrombosis/embolism, 2 of pneumonia, and 1 of cardiac ischemia for patients receiving chemotherapy with sorafenib compared with 7 grade 5 toxicities including 4 of infection, 1 of thrombosis/embolism, and 2 of cardiac ischemia for patients receiving chemotherapy alone (65).

While single-agent sorafenib may be beneficial in patients with advanced NSCLC, these data would suggest that combination chemotherapy with sorafenib does not improve survival for patients with advanced NSCLC. A second large phase III trial, NExUS, remains open, evaluating chemotherapy with gemcitabine and cisplatin with or without sorafenib in the same patient population. Patients with squamous cell histology are no longer eligible for this study based on the data from the ESCAPE trial. 


\section{VANDETANIB}

Vandetanib (AZD6474, Zactima) is an oral inhibitor of angiogenesis targeting VEGFR-2, VEGFR-3, tumor growth with activity against RET, and epidermal growth factor receptor (EGFR/HER1) $(66,67)$. Vandetanib has been shown to be active against a wide range of tumor cells in preclinical studies (68). In phase I studies, single-agent vandetanib was well tolerated in patients with a variety of solid tumors, including NSCLC $(69,70)$. The recommended dose is $300 \mathrm{mg}$ daily.

\section{Single-Agent Vandetanib}

Therapy with vandetanib (100, 200, or $300 \mathrm{mg}$ daily) was evaluated in a randomized phase II dose-finding study of 53 Japanese patients with NSCLC. Toxicities included rash, diarrhea, hypertension, and asymptomatic QTc prolongation. One patient died from treatment-related interstitial lung disease. Overall, there was a $13.2 \%$ PR. A higher RR was noted at the $100 \mathrm{mg}(17.6 \%)$ and $300 \mathrm{mg}$ dose $(16.7 \%)$, although this was thought to be due to a higher number of patients having failed two prior chemotherapy regimens at the 200-mg dose level, where the RR was $5.6 \%$. Time to progression was 8.3 weeks at the $100-\mathrm{mg}$ dose and 12.3 weeks at both the $200-\mathrm{mg}$ and $300-\mathrm{mg}$ doses. Biological correlates were measured as part of this trial; plasma VEGF showed a trend to increase during the study period, while plasma VEGFR-2 appeared to decrease and Tie-2 (a receptor tyrosine kinase expressed principally on the vascular endothelium) levels did not change. Baseline plasma VEGF levels appeared to be lower in patients experiencing a clinical benefit from treatment (71). In a randomized phase II trial of 168 patients with NSCLC, single-agent vandetanib was compared with gefitinib in patients after failure of first- or secondline platinum-based therapy. Of note, patients with hemoptysis, thromboses, squamous cell carcinoma, and brain metastases were permitted to enter this trial. Median PFS was 11 weeks for vandetanib compared with 8.1 weeks for patients receiving gefitinib. Objective responses were seen in $8 \%$ of vandetanibcompared with $1 \%$ of gefitinib-treated patients, with disease control achieved in 37/83 (45\%) versus $29 / 85$ (34\%) of patients, respectively. The most common toxicities ( $>10 \%$ of patients) seen in patients treated with vandetinib included nausea, diarrhea, rash, headache, dizziness, hypertension, and asymptomatic QTc prolongation. On progression, patients were allowed to switch to the alternative regimen after a 4-week washout period. In patients who switched therapies; disease control more than 8 weeks was seen in $16 / 37(43 \%)$ patients who switched to vandetanib and in 7/29 (24\%) patients who switched to gefitinib. OS was not significantly different between treatment arms (6.1 mo for vandetanib versus 7.4 mo for gefitinib-treated patients) (72).

\section{Combination Therapy}

In a phase II randomized placebo-controlled trial of 127 patients with advanced NSCLC who had failed platinum-based chemotherapy, treatment with daily vandetanib (100 or $300 \mathrm{mg}$ ) plus docetaxel was compared with docetaxel alone. Patients with squamous cell histology were permitted to enter the trial, as were patients with clinically stable, treated brain metastases. An initial run-in phase treated patients with vandetanib (100 $\mathrm{mg})$ and docetaxel, and was followed by an additional cohort treated with vandetanib (300 mg) with docetaxel. When no safety concerns were noted, additional patients were randomized to one of three arms (vandetanib $100 \mathrm{mg}$, vandetanib $300 \mathrm{mg}$, or placebo). A PR was seen in $12 \%$ of patients receiving docetaxel alone, $26 \%$ of patients receiving vandetanib $100 \mathrm{mg}$ and docetaxel, and $18 \%$ of patients receiving vandetanib $300 \mathrm{mg}$ and docetaxel. There was no statistically significant difference in OS 13.4 versus 13.1 versus 7.9 months, respectively. Major toxicities were similar to those mentioned previously with the addition of neutropenia. All toxicities were more frequent and severe in patients receiving vandetanib $300 \mathrm{mg}$ with docetaxel. Nonfatal hemoptysis was reported in seven patients. Six deaths occurred on study unrelated to the trial medication (73). The results of this study have led to a phase III trial comparing vandetanib plus docetaxel to docetaxel alone as a second-line therapy in patients with advanced NSCLC. In a second randomized phase II trial, 181 chemotherapy-naïve patients with advanced NSCLC were randomized to one of three treatments - single agent vandetanib, vandetanib plus paclitaxel and carboplatin, or paclitaxel and carboplatin alone. Patients with CNS metastases and squamous-cell histology were permitted to enter this trial. The objective response rates were $7 \%$ for vandetanib alone, $32 \%$ for combination therapy, and $25 \%$ for chemotherapy alone. Combination therapy with vandetanib with carboplatin and paclitaxel prolonged PFS compared with carboplatin and paclitaxel alone ( 24 versus $23 \mathrm{wk}$; HR 0.75 ; $95 \%$ confidence interval [CI], 0.05-01.15; $P=0.098)$. The vandetanib monotherapy arm was stopped early after a planned interim analysis of PFS met criteria for discontinuation. OS was not significantly different for vandetanib plus chemotherapy versus chemotherapy alone. Contrary to the ECOG 4,599 trial an unplanned exploratory analysis suggested a benefit for female patients receiving vandetanib with chemotherapy compared with chemotherapy alone. Toxicities, although more common among vandetanib- and chemotherapy-treated patients were similar to those seen with single-agent therapy and included rash, diarrhea, hypertension, and asymptomatic QTc-related events $(74,75)$.

Heymach and coworkers conducted an exploratory analysis measuring baseline VEGF levels in 351 patients $(82 \%$ of trial participants) who participated in the three trials involving vandetanib in combination with chemotherapy listed above. Analysis of VEGF levels from all three trials demonstrated lower risk of disease progression in patients with low baseline levels of VEGF receiving treatment with vandetanib compared with gefitinib or chemotherapy with paclitaxel and carboplatin or docetaxel alone. Those patients with high VEGF levels had a similar benefit from treatment with or without vandetanib (76).

Therefore, single-agent vandetanib has shown promising activity in patients with advanced NSCLC. The improved RR and PFS compared with gefitinib may be due to vandetinib acting on both VEGF and EGFR pathways. Inhibition of VEGF pathways is believed to contribute to the mechanism of action of agents targeting EGFR (77), and increased activity of VEGF pathways is one of the mechanisms via which tumors develop resistance to EGFR inhibitors (78). Preclinical data has shown that dual EGFR and VEGF inhibition has additive effects and can overcome resistance in EGFR inhibitorresistant cells (79). Ongoing phase II and III clinical trials are evaluating single-agent vandetanib and vandetanib in combination with chemotherapy in the first-, second-, and third-line treatment of patients with NSCLC. The potential benefit of lowdose vandetanib with chemotherapy is postulated to be due to lack of EGFR-TKI activity at this dose while maintaining the VEGF-TKI activity.

\section{Sunitinib}

Sunitinib (SU11248, Sutent) is a novel, multi-targeted, small molecule inhibitor of the receptor tyrosine kinases (RTKs) involved in tumor proliferation and angiogenesis, including VEGFR-1, -2, and -3, PDGFR- $\alpha$ and $-\beta$, Flt3, c-kit and the receptor encoded by the ret proto-oncogene (RET; rearranged 
during transfection), and fms-like tyrosine kinase 3 (Flt3) (80). Of note, it has been suggested that combined inhibition of PDGFR and VEGFR-2-mediated signaling may be particularly potent in the inhibition of angiogenesis (81). Sunitinib has demonstrated antitumor activity against a variety of tumor cell lines, including NSCLC, in pre-clinical studies $(82,83)$. The recommended dose of sunitinib is $50 \mathrm{mg}$ daily for 4 consecutive weeks of a 6-week cycle. The 2-week rest period is required due to the long half-life of sunitinib malate $(80 \mathrm{~h}$ for the active metabolite), which causes drug accumulation. However, in the clinical setting this administration schedule may allow for vascular re-growth and tumor progression.

\section{Single-Agent Sunitinib}

A phase II trial of 63 patients with NSCLC evaluated singleagent sunitinib as a second- or third-line therapy. Patients with recent grade 3 hemorrhage or gross hemoptysis, brain metastases, uncontrolled hypertension, cardiac disease, prior cerebrovascular accident, or pulmonary embolism, or patients who had undergone surgery within 4 weeks of study entry, were excluded from this trial. Patients with squamous cell histology were eligible. Treatment with sunitinib resulted in a $11.1 \%$ PR (95\% CI, $4.6-21.6 \%$ ) and $28.6 \%$ of patients with SD. PFS was 12 weeks (95\% CI, 10.0-16.0 weeks), overall survival was 23.4 weeks (95\% CI, 17-28.3 weeks) and 1-year survival was $20.2 \%$ (95\% CI, 10-30.4\%). Major toxicities (> 10\% of patients) included fatigue/asthenia, pain/myalgia, nausea and vomiting, dyspnea, and stomatitis/mucosal inflammation. There were three hemorrhage-related deaths on study, two related to sunitinib. Two additional deaths were believed to be related to study medication; one due to disseminated intravascular coagulation and another due to pneumothorax (84). Another phase II study evaluated sunitinib in 47 patients with previously treated NSCLC. Patients with brain metastases and significant hemoptysis were excluded. One patient had a confirmed PR, and nine patients had SD. The PFS was 12.3 weeks and OS was 37.1 weeks. Adverse events were similar to those mentioned above in addition to congestive heart failure, hypomagnesemia, and hypoxic respiratory failure (85).

\section{Combination Therapy}

A phase I study in untreated patients with advanced NSCLC evaluated sunitinib $(37.5 \mathrm{mg}$ or $50 \mathrm{mg}$ ) in combination with cisplatin and gemcitabine. No dose-limiting toxicities were seen at the sunitinib $37.5 \mathrm{mg}$ dose, while two were noted (neutropenia and infection) at the 50-mg dose. Additional grade 3/4 toxicities included anemia, neutropenia, and thrombocytopenia. Three patients achieved a PR at the 50-mg dose level. Sunitinib $37.5 \mathrm{mg}$ appears to be the recommended dose with this chemotherapy schedule. Studies with the higher dose of gemcitabine and sunitinib administration on a continuous dosing schedule are ongoing (86). A second phase I study in 37 patients with advanced solid tumors, including 13 patients with NSCLC, evaluated sunitinib in combination with docetaxel. Neutropenia (with or without fever) was seen in five patients. One patient had pulseless electrical activity and pulmonary hemorrhage. With greater than $50 \%$ SD seen at both dose levels, the combination of sunitinib and docetaxel has been recommended with ongoing pharmacokinetic and efficacy studies to determine the utility of further evaluation of this regimen (87). Ongoing phase I and II trials are investigating the addition of sunitinib to standard first-line regimens (carboplatin/paclitaxel; carboplatin/ paclitaxel/bevacizumab; carboplatin or cisplatin/pemetrexed; gemcitabine/cisplatin). A phase III trial is evaluating sunitinib in combination with erlotinib versus erlotinib alone in 956 patients in the second- or third-line settings.

\section{Cediranib}

Cediranib (AZD2171, Recentin) is a potent inhibitor of both VEGFR-1 and VEGFR-2; it also has activity against c-kit, PDGFR- $\beta$, and Flt-4 at nanomolar concentrations, but is selective against other serine/threonine kinases studied. Cediranib has been shown to inhibit VEGF signaling with once-daily oral dosing. Cedrinib $45 \mathrm{mg}$ once daily has been shown to be well tolerated in patients with a broad range of solid tumors (88). The most common toxicities include diarrhea, dysphonia, and hypertension (88).

\section{Combination Therapy}

Cediranib (20,30, or $45 \mathrm{mg}$ daily) has been evaluated in phase I studies in combination with four chemotherapy regimens, including pemetrexed and docetaxel, two agents commonly employed in treatment of patients with NSCLC. In this group of heavily pretreated patients with advanced solid tumors, the safety profile of cediranib was similar to that observed with singleagent cediranib, with the most common grade 3 toxicities including diarrhea, fatigue, and hypertension. Response rates were promising and cediranib did not appear to affect the pharmacokinetic profile of either agent (89). A second phase I study in patients with previously treated advanced solid tumors evaluated cediranib in combination with gefitinib. Cediranib $30 \mathrm{mg}$ or lower appeared to be well tolerated. The most common toxicities were diarrhea, rash, abdominal pain, and hypertension, with only the latter side effect attributed to cediranib (90). A phase I study in 20 chemotherapy-naïve patients with advanced NSCLC evaluated cediranib (30 or $45 \mathrm{mg}$ ) in combination with carboplatin and paclitaxel every 3 weeks. Patients with prior hemoptysis or bleeding were ineligible for this trial, but those on anticoagulation were allowed. The most common toxicities ( $>25 \%$ of patients) were hypertension, fatigue, anorexia, diarrhea, myalgias, and neutropenia. These toxicities were compared with patients receiving carboplatin and paclitaxel from the NCIC BR18 trial and were found to be more frequent and severe. At the 45-mg dose, four patients were hospitalized for febrile neutropenia, three patients had pulmonary emboli, and one patient had grade 3 hemoptysis. Four patients at the 30-mg dose were hospitalized for GI toxicities. Three patients discontinued therapy for arthralgias and neuralgias, fatigue and thrombosis, and acute cholecystitis. Hypertension occurred in 15 patients, 11 with no prior history. There were 9 PR $(45 \%)$ and 11 patients with SD. Median time to progression was 7.6 months. The pharmacokinetics of paclitaxel, and carboplatin were not affected by co-administration of cediranib (91). A second phase I study, conducted by the same investigators in the same population, evaluated cediranib (30 or $45 \mathrm{mg}$ ) in combination with gemcitabine and cisplatin every 3 weeks. A total of 14 patients were enrolled; 5 patients at the $30-\mathrm{mg}$ dose and 9 patients at the $45-\mathrm{mg}$ dose. Toxicities including diarrhea, fatigue, hypertension, and voice changes were seen at both levels. Grade 4 toxicities included one patient with reversible ischemia and another with fatigue. Cediranib did not appear to affect gemcitabine pharmacokinetics. Responses were seen at both dose levels. Further testing of this combination has been recommended with cediranib $30 \mathrm{mg}$ (92). The National Cancer Institute of Canada (NCI-C) has recently closed BR-24 (a randomized, double-blind, placebo-controlled trial of cediranib in combination with carboplatin and paclitaxel) due to excessive toxicities, raising the question of cediranib in combination with chemotherapy in the treatment of patients with advanced NSCLC.

\section{OTHER THERAPIES}

Motesanib (AMG 706) is a potent, oral, multikinase inhibitor with activity against VEGFR-1, -2, and -3; PDGFR; kit; and Ret. 
Preclinical studies demonstrated inhibition of VEGF-induced angiogenesis and inhibition of tumor growth in vivo (93). A phase I study evaluated motesanib by DCE-MRI in 65 patients with advanced solid tumors. The most frequent toxicities $(>10 \%$ of patients) were hypertension, fatigue, diarrhea, nausea, vomiting, and headache. Most events were mild to moderate in severity and reversible. Of note, early trials suggested that there was cause for concern with some patients who had received motesanib developing cholecystitis and gallbladder enlargement. Ongoing studies have continued to gather data on this issue, and the latest reports suggest that these events are manageable. Of 56 evaluable patients, there was a $4 \% \mathrm{PR}$ and $61 \%$ SD rate. DCE-MRI showed reductions up to $61 \%$ in AUC on Day 21 of treatment. Motesanib $125 \mathrm{mg}$ daily was well tolerated and has been recommended for phase II studies (94). A phase I trial evaluated motesanib in combination with gemcitabine in 26 patients, including 2 with lung cancer. Motesanib pharmacokinetics did not appear to be affected by the schedule of gemcitabine administration. There were two dose-limiting toxicities: grade 4 neutropenia and grade 3 deep vein thrombosis. Other toxicities ( $>10 \%$ of patients) included lethargy, fatigue, headache, nausea, and diarrhea. There were two unconfirmed PR and seven patients with SD. Further testing of this regimen has been recommended (95). In another phase I study of 36 patients with advanced solid tumors, including 19 with NSCLC, motesanib was combined with panitumumab, cisplatin, and gemcitabine. Forty-two percent of patients had received one prior chemotherapy. There was a $39 \%$ rate of thromboemolism, and one grade 5 pulmonary embolism was seen. Additional toxicities ( $>25 \%$ of patients) included nausea, fatigue, and hypertension. Of 29 patients evaluable for response, there was $1 \mathrm{CR}, 31 \% \mathrm{PR}$ (6 seen in patients with NSCLC), and $59 \%$ SD. Motesanib pharmacokinetics at $125 \mathrm{mg}$ daily were not affected by other therapies. Although this combination appears to be effective, the rate of thromboemolism needs to be compared with treatment with cisplatin plus gemcitabine alone before further testing can be recommended $(96,97)$. A phase III, randomized, double-blind, placebo-controlled trial will randomize a planned 1,240 chemotherapy-naïve patients with advanced NSCLC to carboplatin and paclitaxel with or without motesanib. Patients with untreated or symptomatic CNS metastases, a history of pulmonary hemorrhage or gross hemoptysis within 6 months before randomization, or uncontrolled hypertension are not eligible to enter this trial. Patients with squamouscell histology are eligible. A phase II head-to-head trial is ongoing, comparing first-line motesanib plus carboplatin and paclitaxel to bevacizumab plus carboplatin and paclitaxel. Eligibility criteria for this trial reflect the bevacizumab eligibility profile: nonsquamous NSCLC, no history of or current CNS metastases, no history of pulmonary hemorrhage or gross hemoptysis, and no uncontrolled hypertension.

Axitinib (AG-013736) is a small-molecule tyrosine kinase inhibitor of VEGFR-1, -2, and -3; PDGR- $\beta$; and c-kit. A phase I dose escalation study evaluated axitinib $(5-30 \mathrm{mg})$ in 36 patients with solid tumors (including NSCLC) who were refractory to standard therapy. The maximum tolerated dose and the recommended dose for phase II/III trials is $5 \mathrm{mg}$ twice daily. There were three confirmed PR with other evidence of antitumor activity. Dose limiting toxicities ( $>10 \%$ of patients) associated with axitinib therapy included hypertension, fatigue, nausea, vomiting, diarrhea, headache, stomatitis, and erythema; however, the complete adverse event profile is not yet known. Cavitation of lung lesions, similar to what has been seen with bevacizumab, was observed in the two patients with NSCLC, both subsequently died with hemoptysis (one was believed to be axitinib related) (98). A phase II trial evaluated the activity and safety of axitinib in 32 patients with advanced NSCLC. Patients may have had prior chemotherapy, radiation therapy, or surgery; $13 \%$ of patients were treatment naïve. Median duration of response was 9.4 months, PFS was 5.8 months, and OS was 12.8 months. Three responses were noted. Toxicities (occurring in $5 \%$ of patients) included fatigue, diarrhea, hypertension, and hyponatremia (99).

Pazopanib (GW786034) is an oral, small-molecule tyrosine kinase inhibitor targeting VEGFR-1, -2 , and 3; PDGFR- $\alpha$ and $-\beta$; and c-kit. A phase I study in 43 patients with advanced solid tumors (including NSCLC) evaluated pazopanib in doses ranging from $50 \mathrm{mg}$ three times weekly to $2,000 \mathrm{mg}$ daily. The most common adverse events were nausea, diarrhea, fatigue, hypertension, anorexia, and vomiting. Hair depigmentation was observed at higher doses. Tumor shrinkage was noted in patients with renal cell cancer. One patient with NSCLC was included in the six patients with SD who remained on therapy for 6 months or more (100). Neoadjuvant pazopanib $(800 \mathrm{mg})$ was administered for 2 to 6 weeks before scheduled surgery for patients with stage IA and stage IB NSCLC. Tumor measurements and plasma cytokine/angiogenic factors were measured before and after treatment. Measurements from 19 paired samples demonstrated decrease in serum VEGFR-2 and increases in additional cytokine/angiogenic factors. There was a strong correlation between serum VEGFR-2 and tumor shrinkage, making this a potential marker for treatment response (101). However, the efficacy of pazopanib in the treatment of patients with NSCLC is still to be determined.

XL647 is another oral, small-molecule tyrosine kinase inhibitor with activity against VEGFR-2, EGFR, erbB2/HER2, and EphB4. Initial phase I studies administered XL647 daily for 5 days of a 14-day schedule to 41 patients with advanced solid tumors. The maximal tolerated dose was $350 \mathrm{mg}$ daily for 5 days. One patient with NSCLC had a PR, and an additional 14 patients had SD. Toxicities included diarrhea, fatigue, rash, and QTc prolongation $(102,103)$. In a second phase I study by the same group, XL647 was administered on a continuous daily schedule to patients with advanced solid tumors. A total of 31 patients were enrolled at increasing doses $(75 \mathrm{mg}, 150 \mathrm{mg}$, $200 \mathrm{mg}, 300 \mathrm{mg}$, and $350 \mathrm{mg}$ ). The maximum tolerated dose was $300 \mathrm{mg}$ daily. Nine patients remain on study, with the majority withdrawing for disease progression; 12 patients have had SD more than 3 months. The most common toxicities included rash, diarrhea, fatigue, dysgeusia, and asymptomatic QTc prolongation. Pharmacokinetics indicate the drug has rapid absorption with steady stay levels by Day $15(103,104)$. In a Simon twostage study XL647 (300 mg daily for 28-d cycle) was administered to 23 patients with NSCLC who relapsed after initial benefit from erlotinib or gefitinib. The most common toxicities were diarrhea, rash, nausea, and fatigue. Two patients discontinued treatment - one due to a grade 4 pulmonary embolus and another due to a grade 2 increased creatinine. There has been $1 \mathrm{PR}$ and 7 patients with SD. Patients have reported improvement in symptoms while on study. Accrual continues with stage two of this study (105). A second trial by the same investigators administered XL647 (350 mg daily, Days 1-5 every $2 \mathrm{wk}$ ) to 41 chemotherapy-naïve patients with NSCLC meeting at least one of the eligibility criteria: Asian, female, minimal ( $<15$ pack years), or no smoking history. Of 36 patients evaluable for response, there was a $28 \% \mathrm{PR}$ and $36 \%$ of patients had $\mathrm{SD}(\geqslant 3 \mathrm{mo})$. Seventy percent of patients with a PR had an EGFR mutation detected in tumor tissue (106). Phase II clinical studies with XL647 in patients with NSCLC are ongoing.

\section{CONCLUSIONS}

As our knowledge of cell biology improves, we are able to identify therapies that more precisely affect the target of 
interest, allowing for a more rational approach to clinical trial design. Inhibition of angiogenesis continues to be an attractive target in the treatment of patients with NSCLC. Based on randomized phase II and III trials, bevacizumab is the only antiangiogenic therapy approved to date for the treatment of patients with NSCLC $(20,21)$. The multitude of ongoing clinical trials that have added bevacizumab to standard chemotherapy illustrates the continued interest in VEGF as a therapeutic target. The small-molecule receptor tyrosine kinase inhibitors have several targets, including VEGF. While several of these agents have shown activity in phase II trials, the studies are small, and larger phase III trials that are currently underway will determine their role in the treatment of patients with NSCLC. An important aspect of several of these studies continues to be the inclusion of biological correlates to determine indicators that are prognostic and predictive of a benefit from therapy. However, no definitive markers have been identified to date. Low baseline VEGF was found to be predictive of lower risk of disease progression in patients treated with vandetanib (76) but not bevacizumab (21), where ICAM levels where found to be predictive while VEGFR-2 was found to correlate with tumor shrinkage in pazopanib-treated patients (101). The increased sophistication of preclinical models and the enrollment of patients in clinical trials that include measurements of potential biological correlates will help identify patients that may benefit from therapy with angiogenesis inhibitors as well as determine potential mechanisms of resistance to therapy.

Conflict of Interest Statement: L.H. does not have a financial relationship with a commercial entity that has an interest in the subject of this manuscript. A.B.S. reports receiving grant support from Genentech, OSI, Pfizer, Eli-Lilly, SanofiAventis, Bayer, AstraZeneca, Bristol-Myers Squibb, Cyclacel, Wyeth, and Amgen. He received lecture fees from Genentech and Eli-Lilly, and consulting fees from Genentech, OSI, Bristol-Myers Squibb, Eli-Lilly, Sanofi-Aventis, Pfizer, Bayer, AstraZeneca, and Amgen.

\section{References}

1. Jemal A, Siegel R, Ward E, Hao Y, Xu J, Murray T, Thun MJ. Cancer statistics, 2008. CA Cancer J Clin 2008;58:71-96.

2. Schiller JH, Harrington D, Belani CP, Langer C, Sandler A, Krook J, Zhu J, Johnson DH. Comparison of four chemotherapy regimens for advanced non-small-cell lung cancer. N Engl J Med 2002;346:92-98.

3. Carmeliet P. Angiogenesis in life, disease and medicine. Nature 2005; 438:932-936.

4. Folkman J. Tumor angiogenesis: therapeutic implications. N Engl J Med 1971;285:1182-1186.

5. Hanahan D, Folkman J. Patterns and emerging mechanisms of the angiogenic switch during tumorigenesis. Cell 1996;86:353-364.

6. Kerbel RS. Antiangiogenic therapy: a universal chemosensitization strategy for cancer? Science 2006;312:1171-1175.

7. Baluk P, Hashizume H, McDonald DM. Cellular abnormalities of blood vessels as targets in cancer. Curr Opin Genet Dev 2005;15:102-111.

8. Yano S, Shinohara H, Herbst RS, Kuniyasu H, Bucana CD, Ellis LM, Davis DW, McConkey DJ, Fidler IJ. Expression of vascular endothelial growth factor is necessary but not sufficient for production and growth of brain metastasis. Cancer Res 2000;60:4959-4967.

9. Macchiarini P, Fontanini G, Dulmet E, de Montpreville V, Chapelier AR, Cerrina J, Ladurie FL, Dartevelle PG. Angiogenesis: an indicator of metastasis in non-small cell lung cancer invading the thoracic inlet. Ann Thorac Surg 1994;57:1534-1539.

10. Holmgren L, O'Reilly MS, Folkman J. Dormancy of micrometastases: balanced proliferation and apoptosis in the presence of angiogenesis suppression. Nat Med 1995;1:149-153.

11. Fontanini G, Bigini D, Vignati S, Basolo F, Mussi A, Lucchi M, Chine S, Angeletti CA, Harris AL, Bevilacqua G. Microvessel count predicts metastatic disease and survival in non-small cell lung cancer. J Pathol 1995;177:57-63.

12. Fontanini G, Lucchi M, Vignati S, Mussi A, Ciardiello F, De Laurentiis M, De Placido S, Basolo F, Angeletti CA, Bevilacqua G. Angiogenesis as a prognostic indicator of survival in non-small-cell lung carcinoma: a prospective study. J Natl Cancer Inst 1997;89:881-886.
13. Kerbel RS. Tumor angiogenesis. $N$ Engl J Med 2008;358:2039-2049.

14. Imoto $\mathrm{H}$, Osaki $\mathrm{T}$, Taga $\mathrm{S}$, Ohgami A, Ichiyoshi $\mathrm{Y}$, Yasumoto $\mathrm{K}$. Vascular endothelial growth factor expression in non-small-cell lung cancer: prognostic significance in squamous cell carcinoma. $J$ Thorac Cardiovasc Surg 1998;115:1007-1014.

15. Volm M, Koomagi R, Mattern J. Prognostic value of vascular endothelial growth factor and its receptor Flt-1 in squamous cell lung cancer. Int J Cancer 1997;74:64-68.

16. Fontanini G, Faviana P, Lucchi M, Boldrini L, Mussi A, Camacci T, Mariani MA, Angeletti CA, Basolo F, Pingitore R. A high vascular count and overexpression of vascular endothelial growth factor are associated with unfavourable prognosis in operated small cell lung carcinoma. Br J Cancer 2002;86:558-563.

17. Fontanini G, Vignati S, Boldrini L, Chine S, Silvestri V, Lucchi M, Mussi A, Angeletti CA, Bevilacqua G. Vascular endothelial growth factor is associated with neovascularization and influences progression of nonsmall cell lung carcinoma. Clin Cancer Res 1997;3:861-865.

18. Ferrara N, Hillan KJ, Gerber HP, Novotny W. Discovery and development of bevacizumab, an anti-VEGF antibody for treating cancer. Nat Rev Drug Discov 2004;3:391-400.

19. Presta LG, Chen H, O'Connor SJ, Chisholm V, Meng YG, Krummen L, Winkler M, Ferrara N. Humanization of an anti-vascular endothelial growth factor monoclonal antibody for the therapy of solid tumors and other disorders. Cancer Res 1997;57:4593-4599.

20. Johnson DH, Fehrenbacher L, Novotny WF, Herbst RS, Nemunaitis JJ, Jablons DM, Langer CJ, DeVore RF, 3rd, Gaudreault J, et al. Randomized phase II trial comparing bevacizumab plus carboplatin and paclitaxel with carboplatin and paclitaxel alone in previously untreated locally advanced or metastatic non-small-cell lung cancer. J Clin Oncol 2004;22:2184-2191.

21. Sandler A, Gray R, Perry MC, Brahmer J, Schiller JH, Dowlati A, Lilenbaum R, Johnson DH. Paclitaxel-carboplatin alone or with bevacizumab for non-small-cell lung cancer. N Engl J Med 2006;355:2542-2550.

22. Dowlati A, Gray R, Johnson DH, Schiller JH, Brahmer J, Sandler AB. Prospective correlative assessment of biomarkers in E4599 randomized phase II/III trial of carboplatin and paclitaxel $\{+/-\}$ bevacizumab in advanced non-small cell lung cancer (NSCLC) [abstract]. ASCO Meeting Abstracts 2006;24:7027.

23. Ramalingam SS, Dahlberg SE, Langer CJ, Gray R, Belani CP, Brahmer JR, Sandler AB, Schiller JH, Johnson DH. Outcomes for elderly, advanced-stage non small-cell lung cancer patients treated with bevacizumab in combination with carboplatin and paclitaxel: analysis of Eastern Cooperative Oncology Group Trial 4599. J Clin Oncol 2008;26:60-65.

24. Pignon JP, Tribodet H, Scagliotti GV, Douillard JY, Shepherd FA, Stephens RJ, Dunant A, Torri V, Rosell R, Seymour L, et al. Lung adjuvant cisplatin evaluation: a pooled analysis by the LACE Collaborative Group. J Clin Oncol 2008;26:3552-3559.

25. Manegold C, von Pawel J, Zatloukal P, Ramlau R, Gorbounova V, Hirsch V, Leighl N, Mezger J, Archer V, Reck M, et al.: BO17704 Study Group. Randomised, double-blind multicentre phase III study of bevacizumab in combination with cisplatin and gemcitabine in chemotherapy-naive patients with advanced or recurrent non-squamous non-small cell lung cancer (NSCLC): BO17704 [abstract]. ASCO Meeting Abstracts 2007;25: LBA7514.

26. Reynolds C, Barrera D, Vu DQ, Jotte R, Spira AI, Weissman CH, Boehm KA, Ilegbodu D, Pritchard S, Asmar L. An open-label, phase II trial of nanoparticle albumin bound paclitaxel (nab-paclitaxel), carboplatin, and bevacizumab in first-line patients with advanced nonsquamous non-small cell lung cancer (NSCLC) [abstract]. ASCO Meeting Abstracts 2007;25:7610.

27. William WN Jr, Kies MS, Fossella FV, Gladish G, Heymach JV, Glisson BS, Tse WH, Liu D, Herbst RS, Lippman SM. Phase II study of bevacizumab in combination with docetaxel and carboplatin in patients with metastatic non-small cell lung cancer (NSCLC) [abstract]. ASCO Meeting Abstracts 2007;25:18098.

28. Ferrer N, Paredes A, Munoz-Langa JM, Mendez M, Cobo M, de-Portugal T, Giner V, Garcia S, Gallego R, Torrego J. Bevacizumab in combination with cisplatin and docetaxel as first line treatment of patients (pts) with advanced or metastatic, non squamous, non-smallcell lung cancer (NSCLC) [abstract]. ASCO Meeting Abstracts 2008;26: 19109.

29. Dalsania CJ, Hageboutros A, Harris E, Krieger K, Vora C, Stevenson J. Phase II trial of bevacizumab plus pemetrexed and carboplatin in previously untreated advanced nonsquamous non-small cell lung cancer [abstract]. ASCO Meeting Abstracts 2007;25:18163. 
30. Patel JD, Hensing TA, Villafor V, Hart E, Bonomi P. Pemetrexed and carboplatin plus bevacizumab for advanced non-squamous non-small cell lung cancer (NSCLC): preliminary results [abstract]. ASCO Meeting Abstracts 2007;25:7601.

31. Heist RS, Fidias P, Huberman M, Temel J, Sequist L, Lynch TJ. Phase II trial of oxaliplatin, pemetrexed, and bevacizumab in previouslytreated advanced non-small cell lung cancer (NSCLC) [abstract]. ASCO Meeting Abstracts 2007;25:7700.

32. Waples JM, Auerbach M, Boccia R, Wiggans RG, Steis R; International Oncology Network. A phase II study of oxaliplatin and pemetrexed plus bevacizumab in advanced non-squamous non-small cell lung cancer [abstracts]. ASCO Meeting Abstracts 2007;25:18025.

33. Davila E, Lilenbaum R, Raez L, Seigel L, Tseng J, Graham P. Phase II trial of oxaliplatin and gemcitabine with bevacizumab in first-line advanced non-small cell lung cancer (NSCLC) [abstracts]. ASCO Meeting Abstracts 2006;24:17009.

34. Kraut MJ. Phase II study of gemcitabine and carboplatin plus bevacizumab for stage III/IV non-small cell lung cancer: preliminary safety data [abstract]. ASCO Meeting Abstracts 2006;24:17091.

35. Rizvi NA, Rusch V, Zhao B, Senturk E, Schwartz L, Fury M, Downey R, Rizk N, Krug L, Kris MG. Single agent bevacizumab and bevacizumab in combination with docetaxel and cisplatin as induction therapy for resectable IB-IIIA non-small cell lung cancer [abstract]. ASCO Meeting Abstracts 2007;25:18045.

36. Adjei AA, Mandrekar SJ, Dy GK, Molina JR, Adjei AA, Gandara DR, Ziegler KLA, Stella PJ, Rowland KM Jr, Schild SR, Zinner R. A phase II second-line study of pemetrexed (pem) in combination with bevacizumab (bev) in patients with advanced non-small cell lung cancer (NSCLC): an NCCTG and SWOG study [abstract]. ASCO Meeting Abstracts 2008;26:8080.

37. Hanna N, Shepherd FA, Fossella FV, Pereira JR, De Marinis F, von Pawel J, Gatzemeier U, Tsao TC, Pless M, Muller T, Lim HL, Desch $\mathrm{C}$, Szondy $\mathrm{K}$, et al. Randomized phase III trial of pemetrexed versus docetaxel in patients with non-small-cell lung cancer previously treated with chemotherapy. J Clin Oncol 2004;22:1589-1597.

38. Akerley WL, Langer CJ, Oh Y, Strickland DK, Royer SJ, Xia Q, Mu Y, Huang J, Socinski MA. Acceptable safety of bevacizumab therapy in patients with brain metastases due to non-small cell lung cancer [abstract]. ASCO Meeting Abstracts 2008;26:8043.

39. Dansin E, Mezger J, Isla D, Barlesi F, Bearz A, Lopez PG, Laskin JJ, Pavlakis N, Thatcher N, Crino L. Safety of bevacizumab-based therapy as first-line treatment of patients with advanced or recurrent non-squamous non-small cell lung cancer (NSCLC): MO19390 (SAiL) [abstract]. ASCO Meeting Abstracts 2008;26:8085.

40. Griesinger F, Laskin JJ, Pavlakis N; MO19390 Study Group. Safety of firstline bevacizumab-based therapy with concomitant cardiovascular or anticoagulation medication in advanced or recurrent non-squamous non-small cell lung cancer (NSCLC) in MO19390 (SAiL) [abstract]. ASCO Meeting Abstracts 2008;26:8049.

41. Lynch TJ, Brahmer J, Fischbach N, Garst J, Kumar P, Spigel DR, Teng S, Vidaver R, Wang L, Navarro W; ARIES Investigators. Preliminary treatment patterns and safety outcomes for non-small cell lung cancer (NSCLC) from ARIES, a bevacizumab treatment observational cohort study (OCS) [abstract]. ASCO Meeting Abstracts 2008;26:8077.

42. Shepherd FA, Rodrigues Pereira J, Ciuleanu T, Tan EH, Hirsh V, Thongprasert S, Campos D, Maoleekoonpiroj S, Smylie M, Martins $\mathrm{R}$, et al. Erlotinib in previously treated non-small-cell lung cancer. N Engl J Med 2005;353:123-132.

43. Sandler A, Herbst R. Combining targeted agents: blocking the epidermal growth factor and vascular endothelial growth factor pathways. Clin Cancer Res 2006;12:4421s-4425s.

44. Herbst RS, Johnson DH, Mininberg E, Carbone DP, Henderson T, Kim ES, Blumenschein G Jr, Lee JJ, Liu DD, Truong MT, et al. Phase I/II trial evaluating the anti-vascular endothelial growth factor monoclonal antibody bevacizumab in combination with the HER-1/epidermal growth factor receptor tyrosine kinase inhibitor erlotinib for patients with recurrent non-small-cell lung cancer. J Clin Oncol 2005;23: 2544-2555.

45. Salmon JS, Sandler A, Billheimer D, Herbst RS, Tran HT, Tsao A, Dang TP. MALDI-TOF mass spectrometry proteomic profiling to discriminate response to the combination of bevacizumab and erlotinib in non-small cell lung cancer (NSCLC) [abstract]. ASCO Meeting Abstracts 2005;23:7022.

46. Herbst RS, O'Neill VJ, Fehrenbacher L, Belani CP, Bonomi PD, Hart L, Melnyk O, Ramies D, Lin M, Sandler A. Phase II study of efficacy and safety of bevacizumab in combination with chemotherapy or erlotinib compared with chemotherapy alone for treatment of recurrent or refractory non small-cell lung cancer. J Clin Oncol 2007;25: 4743-4750.

47. Polikoff J, Hainsworth JD, Fehrenbacher L, Royer-Joo S, Mu Y, Strickland DK, Miller VA. Safety of bevacizumab (Bv) therapy in combination with chemotherapy in subjects with non-small cell lung cancer (NSCLC) treated on ATLAS [abstract]. ASCO Meeting Abstracts 2008;26:8079.

48. Groen HJ, Smit EF, Dingemans A. A phase II study of erlotinib (E) and bevacizumab (B) in patients (pts) with previously untreated stage IIIB/IV non-small cell lung cancer (NSCLC) [abstract]. ASCO Meeting Abstracts 2007;25:7625.

49. Faoro L, Cohen EE, Govindan R, Kozloff MF, Hoffman PC, Maitland ML, Verel K, Szeto L, Salgia R, Vokes EE. Phase II trial of sequential bevacizumab (B), erlotinib (E) and chemotherapy for first line treatment of clinical stage IIIB or IV non-small cell lung cancer (NSCLC) [abstract]. ASCO Meeting Abstracts 2008;26:19130.

50. Ahmad T, Eisen T. Kinase inhibition with BAY 43-9006 in renal cell carcinoma. Clin Cancer Res 2004;10:6388S-6392S.

51. Wilhelm SM, Carter C, Tang L, Wilkie D, McNabola A, Rong H, Chen C, Zhang X, Vincent P, McHugh M, et al. BAY 43-9006 exhibits broad spectrum oral antitumor activity and targets the RAF/MEK/ ERK pathway and receptor tyrosine kinases involved in tumor progression and angiogenesis. Cancer Res 2004;64:7099-7109.

52. Murphy DA, Makonnen S, Lassoued W, Feldman MD, Carter C, Lee WM. Inhibition of tumor endothelial ERK activation, angiogenesis, and tumor growth by sorafenib (BAY43-9006). Am J Pathol 2006; 169:1875-1885

53. Carter C, Chen C, Brink C, Vincent P, Maxuitenko YY, Gilbert KS, Waud WR, Zhang X. Sorafenib is efficacious and tolerated in combination with cytostatic agents in preclinical models of human non-small cell lung carcinoma. Cancer Chemother Pharmacol 2007;59:183-195.

54. Wilhelm S, Chien DS. BAY 43-9006: preclinical data. Curr Pharm Des 2002;8:2255-2257.

55. Minami H, Kawada K, Ebi H, Kitagawa K, Kim YI, Araki K, Mukai H, Tahara M, Nakajima H, Nakajima K. Phase I and pharmacokinetic study of sorafenib, an oral multikinase inhibitor, in Japanese patients with advanced refractory solid tumors. Cancer Sci 2008;99:1492-1498.

56. Awada A, Hendlisz A, Gil T, Bartholomeus S, Mano M, de Valeriola D, Strumberg D, Brendel E, Haase CG, Schwartz B, et al. Phase I safety and pharmacokinetics of BAY 43-9006 administered for 21 days on/7 days off in patients with advanced, refractory solid tumours. BrJ Cancer 2005;92:1855-1861.

57. Gatzemeier U, Blumenschein G, Fosella F, Simantov R, Elting J, Bigwood D, Cihon F, Reck M. Phase II trial of single-agent sorafenib in patients with advanced non-small cell lung carcinoma [abstract]. ASCO Meeting Abstracts 2006;24:7002.

58. Liu B, Barrett T, Choyke P, Maynard K, Wright J, Kummar S, Murgo A, Doroshow J, Gutierrez M; NCI Bay 43-9006 Working Group. A phase II study of BAY 43-9006 (Sorafenib) in patients with relapsed non-small cell lung cancer (NSCLC) [abstract]. ASCO Meeting Abstracts 2006;24:17119.

59. Bukowski R, Cella D, Gondek K, Escudier B. Effects of sorafenib on symptoms and quality of life: results from a large randomized placebocontrolled study in renal cancer. Am J Clin Oncol 2007;30:220-227.

60. Gutierrez M, Kummar S, Allen D, Turkbey B, Choyke P, Wright J, Kurkjian C, Giaccone G, Doroshow J, Murgo A. A phase II study of multikinase inhibitor sorafenib in patients with relapse non-small cell lung cancer (NSCLC) [abstract]. ASCO Meeting Abstracts 2008;26: 19084

61. Adjei AA, Molina JR, Hillman SL, Luyun RF, Reuter NF, Rowland KM Jr, Jett JR, Mandrekar SJ, Schild SE. A front-line window of opportunity phase II study of sorafenib in patients with advanced non-small cell lung cancer: A North Central Cancer Treatment Group study [abstract]. ASCO Meeting Abstracts 2007;25:7547.

62. Schiller JH, Lee JW, Hanna NH, Traynor AM, Carbone DP. A randomized discontinuation phase II study of sorafenib versus placebo in patients with non-small cell lung cancer who have failed at least two prior chemotherapy regimens: E2501 [abstract]. ASCO Meeting Abstracts 2008;26:8014.

63. Adjei AA, Molina JR, Mandrekar SJ, Marks R, Reid JR, Croghan G, Hanson LJ, Jett JR, Xia C, Lathia C, et al. Phase I trial of sorafenib in combination with gefitinib in patients with refractory or recurrent non-small cell lung cancer. Clin Cancer Res 2007;13:2684-2691.

64. Schiller JH, Flaherty KT, Redlinger M, Binger K, Eun J, Petrenciuc O, O'Dwyer P. Sorafenib combined with carboplatin/paclitaxel for 
advanced non-small cell lung cancer: a phase I subset analysis [abstract]. ASCO Meeting Abstracts 2006;24:7194.

65. Scagliotti G, Von Pawel J, Reck M, Cupit L, Cihon F, DiMatteo S, O'Leary J, Hanna N. Phase III trial comparing carboplatin and paclitaxel with or without sorafenib in chemonaive patients with stage IIIB (with effusion) or IV non-small cell lung cancer. First IASLC-ESMO European Lung Cancer Conference 2008; Geneva, April 23-26, 2008:48.

66. Carlomagno F, Vitagliano D, Guida T, Ciardiello F, Tortora G, Vecchio G, Ryan AJ, Fontanini G, Fusco A, Santoro M. ZD6474, an orally available inhibitor of KDR tyrosine kinase activity, efficiently blocks oncogenic RET kinases. Cancer Res 2002;62:7284-7290.

67. Wedge SR, Ogilvie DJ, Dukes M, Kendrew J, Chester R, Jackson JA, Boffey SJ, Valentine PJ, Curwen JO, Musgrove HL, et al. ZD6474 inhibits vascular endothelial growth factor signaling, angiogenesis, and tumor growth following oral administration. Cancer Res 2002;62: 4645-4655.

68. Ciardiello F, Bianco R, Caputo R, Damiano V, Troiani T, Melisi D, De Vita F, De Placido S, Bianco AR, et al. Antitumor activity of ZD6474, a vascular endothelial growth factor receptor tyrosine kinase inhibitor, in human cancer cells with acquired resistance to antiepidermal growth factor receptor therapy. Clin Cancer Res 2004;10:784-793.

69. Tamura T, Minami H, Yamada Y, Yamamoto N, Shimoyama T, Murakami H, Horiike A, Fujisaka Y, Shinkai T, Tahara M, et al. A phase I dose-escalation study of ZD6474 in Japanese patients with solid, malignant tumors. J Thorac Oncol 2006;1:1002-1009.

70. Holden SN, Eckhardt SG, Basser R, de Boer R, Rischin D, Green M, Rosenthal MA, Wheeler C, Barge A, Hurwitz HI. Clinical evaluation of ZD6474, an orally active inhibitor of VEGF and EGF receptor signaling, in patients with solid, malignant tumors. Ann Oncol 2005;16: 1391-1397.

71. Kiura K, Nakagawa K, Shinkai T, Eguchi K, Ohe Y, Yamamoto N, Tsuboi M, Yokota S, Seto T, Jiang H, et al. A randomized, double-blind, phase IIa dose-finding study of Vandetanib (ZD6474) in Japanese patients with non-small cell lung cancer. $J$ Thorac Oncol 2008;3:386-393.

72. Natale RB, Bodkin D, Govindan R, Sleckman B, Rizvi N, Capo A, Germonpre P, Stockman P, Kennedy S, Ranson M. ZD6474 versus gefitinib in patients with advanced NSCLC: final results from a twopart, double-blind, randomized phase II trial [abstract]. ASCO Meeting Abstracts 2006;24:7000.

73. Heymach JV, Johnson BE, Prager D, Csada E, Roubec J, Pesek M, Spasova I, Belani CP, Bodrogi I, Gadgeel S, et al. Randomized, placebo-controlled phase II study of vandetanib plus docetaxel in previously treated non small-cell lung cancer. J Clin Oncol 2007;25: 4270-4277.

74. Johnson BE, Ma P, West H, Kerr R, Prager D, Sandler A, Herbst RS, Stewart DJ, Dimery IW, Heymach JV. Preliminary phase II safety evaluation of ZD6474, in combination with carboplatin and paclitaxel, as 1st-line treatment in patients with NSCLC [abstract]. ASCO Meeting Abstracts 2005;23:7102.

75. Heymach J, Paz-Ares L, De Braud F, Sebastian M, Stewart DJ, Eberhardt W, Herbst RS, Krebs A, Langmuir P, Johnson BE. Randomized phase II study of vandetanib (VAN) alone or in combination with carboplatin and paclitaxel (CP) as first-line treatment for advanced non-small cell lung cancer (NSCLC) [abstract]. ASCO Meeting Abstracts 2007;25:7544.

76. Heymach JV, Hanrahan EO, Mann H, Langmuir P, Natale RB, Johnson BE, Herbst RS, Ryan AJ. ASCO Meeting Abstracts 2008; 26:8009.

77. Ellis LM. Epidermal growth factor receptor in tumor angiogenesis. Hematol Oncol Clin North Am 2004;18:1007-1021. (viii).

78. Vallbohmer D, Zhang W, Gordon M, Yang DY, Yun J, Press OA, Rhodes KE, Sherrod AE, Iqbal S, Danenberg KD, et al. Molecular determinants of cetuximab efficacy. J Clin Oncol 2005;23:3536-3544.

79. Tabernero J. The role of VEGF and EGFR inhibition: implications for combining anti-VEGF and anti-EGFR agents. Mol Cancer Res 2007; 5:203-220.

80. Abrams TJ, Lee LB, Murray LJ, Pryer NK, Cherrington JM. SU11248 inhibits KIT and platelet-derived growth factor receptor beta in preclinical models of human small cell lung cancer. Mol Cancer Ther 2003;2:471-478.

81. Cabebe E, Wakelee H. Role of anti-angiogenesis agents in treating NSCLC: focus on bevacizumab and VEGFR tyrosine kinase inhibitors. Curr Treat Options Oncol 2007;8:15-27.

82. Mendel DB, Laird AD, Xin X, Louie SG, Christensen JG, Li G, Schreck RE, Abrams TJ, Ngai TJ, Lee LB, et al. In vivo antitumor activity of SU11248, a novel tyrosine kinase inhibitor targeting vascular endothelial growth factor and platelet-derived growth factor receptors: determination of a pharmacokinetic/pharmacodynamic relationship. Clin Cancer Res 2003;9:327-337.

83. Potapova O, Laird AD, Nannini MA, Barone A, Li G, Moss KG, Cherrington JM, Mendel DB. Contribution of individual targets to the antitumor efficacy of the multitargeted receptor tyrosine kinase inhibitor SU11248. Mol Cancer Ther 2006;5:1280-1289.

84. Socinski MA, Novello S, Brahmer JR, Rosell R, Sanchez JM, Belani CP, Govindan R, Atkins JN. Gillenwater HH, Pallares C, et al. Multicenter, phase II trial of sunitinib in previously treated, advanced non-small-cell lung cancer. J Clin Oncol 2008;26:650-656.

85. Brahmer JR, Govindan R, Novello S, Rosell R, Belani CP, Atkins JN, Gillenwater HH, Tye L, Chao R, Socinski MA. Efficacy and safety of continuous daily sunitinib dosing in previously treated advanced nonsmall cell lung cancer (NSCLC): results from a phase II study [abstract]. ASCO Meeting Abstracts 2007;25:7542.

86. Reck M, Frickhofen N, Gatzemeier U, Fuhr H, Lanzalone S, Lechuga MJ, Wang E, Chao R, Felip E. A phase 1 dose escalation study of sunitinib in combination with gemcitabine + cisplatin for advanced non-small cell lung cancer (NSCLC) [abstract]. ASCO Meeting Abstracts 2007;25:18057.

87. Robert F, Sandler A, Schiller JH, Ilagan J, VerMeulen W, Harper K, Liu G, Tye L, Chao R, Traynor A. A phase I dose-escalation and pharmacokinetic (PK) study of sunitinib (SU) plus docetaxel (D) in patients (pts) with advanced solid tumors (STs) [abstract]. ASCO Meeting Abstracts 2007;25:3543.

88. Drevs J, Siegert P, Medinger M, Mross K, Strecker R, Zirrgiebel U, Harder J, Blum H, Robertson J, Jurgensmeier JM, et al. Phase I clinical study of AZD2171, an oral vascular endothelial growth factor signaling inhibitor, in patients with advanced solid tumors. $J$ Clin Oncol 2007;25:3045-3054.

89. Lorusso PM, Heath E, Valdivieso M, Pilat M, Wozniak A, Gadgeel S, Shields A, Puchalski T, Ewesuedo R. Phase I evaluation of AZD2171, a highly potent and selective inhibitor of VEGFR signaling, in combination with selected chemotherapy regimens in patients with advanced solid tumors [abstract]. ASCO Meeting Abstracts 2006;24:3034.

90. van Cruijsen H, Voest EE, van Herpen CML, Hoekman K, Witteveen PO, Punt CJA, Puchalski TA, Fernandes N, Koehler M, Giaccone G. Phase I clinical evaluation of AZD2171 in combination with gefitinib, in patients with advanced tumors [abstract]. ASCO Meeting Abstracts 2005;23:3030.

91. Laurie SA, Gauthier I, Arnold A, Shepherd FA, Ellis PM, Chen E, Goss G, Powers J, Walsh W, Tu D, et al. Phase I and pharmacokinetic study of daily oral AZD2171, an inhibitor of vascular endothelial growth factor tyrosine kinases, in combination with carboplatin and paclitaxel in patients with advanced non-small-cell lung cancer: the National Cancer Institute of Canada clinical trials group. J Clin Oncol 2008;26:1871-1878.

92. Goss GD, Laurie S, Shepherd F, Leighl N, Chen E, Gauthier I, Reaume N, Feld R, Powers J, Seymour L. IND. 175: Phase I study of daily oral AZD2171, a vascular endothelial growth factor receptor inhibitor (VEGFRI), in combination with gemcitabine and cisplatin $(\mathrm{G} / \mathrm{C})$ in patients with advanced non-small cell lung cancer (ANSCLC): a study of the NCIC Clinical Trials Group [abstract]. ASCO Meeting Abstracts 2007;25:7649.

93. Polverino A, Coxon A, Starnes C, Diaz Z, DeMelfi T, Wang L, Bready J, Estrada J, Cattley R, Kaufman S, et al. AMG 706, an oral, multikinase inhibitor that selectively targets vascular endothelial growth factor, platelet-derived growth factor, and kit receptors, potently inhibits angiogenesis and induces regression in tumor xenografts. Cancer Res 2006;66:8715-8721.

94. Rosen L, Kurzrock R, Jackson E, Wathen L, Parson M, Eschenberg M, Mulay M, Purdom M, Yan L, Herbst RS. Safety and pharmacokinetics of AMG 706 in patients with advanced solid tumors [abstract]. ASCO Meeting Abstracts 2006;23:3013.

95. Price TJ, Lipton L, Williams J, McGreivy J, McCoy S, Sun Y, AgueroO'Neill B, Rosenthal MA. Safety and pharmacokinetics (PK) of AMG 706 in combination with gemcitabine for the treatment of patients (pts) with solid tumors [abstract]. ASCO Meeting Abstracts 2007;25:14005.

96. Blumenschein G Jr, Sandler A, O'Rourke T, Eschenberg M, Sun Y, Gladish G, Salgia R, Alden, C, Herbst RS, Reckamp K. Safety and pharmacokinetics (PK) of AMG 706, panitumumab, and carboplatin/ paclitaxel (CP) for the treatment of patients (pts) with advanced nonsmall cell lung cancer (NSCLC) [abstract]. ASCO Meeting Abstracts 2006;24:7119.

97. Crawford J, Burris H, Stephenson J Jr, Otterson G, Stein M, McGreivy J, Sun Y, Ingram M, Yang L, Schwartzberg LS. Safety and pharma- 
cokinetics (PK) of AMG 706 in combination with panitumumab and gemcitabine-cisplatin in patients (pts) with advanced cancer [abstract]. ASCO Meeting Abstracts 2007;25:14057.

98. Rugo HS, Herbst RS, Liu G, Park JW, Kies MS, Steinfeldt HM, Pithavala YK, Reich SD, Freddo JL, Wilding G. Phase I trial of the oral antiangiogenesis agent AG-013736 in patients with advanced solid tumors: pharmacokinetic and clinical results. J Clin Oncol 2005; 23:5474-5483.

99. Schiller JH, Larson T, Ou SI, Limentani SA, Sandler AB, Vokes EE, Kim S, Liau KF, Bycott PW, Olszanski AJ. Efficacy and safety of axitinib (AG-013736; AG) in patients (pts) with advanced non-small cell lung cancer (NSCLC): a phase II trial [abstract]. ASCO Meeting Abstracts 2007;25:7507.

100. Hurwitz H, Dowlati A, Savage S, Fernando N, Lasalvia S, Whitehead B, Suttle B, Collins D, Ho P, Pandite L. Safety, tolerability and pharmacokinetics of oral administration of GW786034 in pts with solid tumors [abstract]. ASCO Meeting Abstracts 2005;23:3012.

101. Nikolinakos P, Altorki N, Guarino M, Tran H, Rajagopalan D, Swann S, Bordogna W, Ottesen L, Yankelevitz D, Heymach JV. Analyses of plasma cytokine/angiogenic factors (C/AFs) profile during preoperative treatment with pazopanib (GW786034) in early-stage non-small cell lung cancer [abstract]. J Clin Oncol 2008;26:7568.

102. Wakelee HA, Adjei AA, Halsey J, Lensing JL, Dugay JD, Hanson LJ, Reid JM, Piens JR, Sikic BI. A phase I dose-escalation and pharmacokinetic (PK) study of a novel spectrum selective kinase inhibitor, XL647, in patients with advanced solid malignancies (ASM) [abstract]. ASCO Meeting Abstracts 2006;24:3044.

103. Wakelee H, Adjei AA, Keer H, Halsey J, Hanson L, Reid J, Hutchison S, Piens J, Lacy S, Sikic BI. A phase I dose-escalation and pharmacokinetic (PK) study of a novel multiple-targeted receptor tyrosine kinase (RTK) inhibitor, XL647, in patients with advanced solid malignancies [abstract]. ASCO Meeting Abstracts 2005;23: 3142.

104. Wakelee HA, Fehling JM, Molina JR, Lensing JL, Funke RP, Miles D, Sikic BI. A phase I study of XL647, an EGFR, HER2, VEGFR2 inhibitor, administered orally daily to patients (pts) with advanced solid malignancies (ASM) [abstract]. ASCO Meeting Abstracts 2008; 26:3528-

105. Miller VA, Wakelee HA, Lara PN, Cho J, Chowhan NM, Costa D, Vrindavanam N, Yanagihara R, Pennell N, Lynch TJ. Activity and tolerance of XL647 in NSCLC patients with acquired resistance to EGFR-TKIs: preliminary results of a phase II trial [abstract]. ASCO Meeting Abstracts 2008;26:8028.

106. Rizvi NA, Kris MG, Miller VA, Krug LM, Bekele S, Dowlati A, Rowland KM, Salgia R, Aggarwal S, Gadgeel M. Activity of XL647 in clinically selected NSCLC patients (pts) enriched for the presence of EGFR mutations: result from Phase 2 [abstract]. ASCO Meeting Abstracts 2008;26:8053. 